\title{
24 COMPLICATING UTOPIAN AND DYSTOPIAN VIEWS OF AUTOMATION: An Investigation of the Work and Knowledge Involved in the Call Center Offshoring Industry in India
}

\author{
Paul R. Devadoss \\ Mike W. Chiasson \\ Lancaster University Management School \\ Lancaster University \\ Lancaster, UK
}

\begin{abstract}
Offshoring is motivated by the relocation and standardization of organizational services to remote locations-typically the so-called developing nations-in order to achieve substantial cost efficiencies. Standardized business practices, aided by information technologies, are assumed to mobilize and recover the service practices in these new contexts. In this paper, we examine the boundary objects and boundary work involved in call center work. Data from several interviews with managers, industry consultants, and agents in the call center industry reveal that the recovery of call center practices in India involves substantial managerial and employee work, in order to manage and stitch together the diverse cultural and practical interests of the various groups. As a result, beneath the automated and simplified appearance of call center work is an underlying complexity of boundary work and boundary objects involved in linking the various participants - both human and nonhuman-into a temporarily stable industry. The result is a complication to both utopian and dystopian views of call center work.
\end{abstract}

Keywords Offshoring, call centers, boundary objects, case study

Please use the following format when citing this chapter:

Devadoss, P. R., and Chiasson, M. W., 2008, in IFIP International Federation for Information Processing, Volume 267, Information Technology in the Service Economy: Challenges and Possibilities for the $21^{\text {st }}$ Century, eds. Barrett, M., Davidson, E., Middleton, C., and DeGross, J. (Boston: Springer), pp. 331-339. 


\section{INTRODUCTION}

The effect of the embedded information technology artefact on the transformation and creation of industrial practices is an important subject. An important topic related to this is the various attempts to use IT in order to redistribute industrial work to other regions through offshoring. Examples include the offshoring of advice and software development to other countries. In these particular situations, various IT artefacts and managerial practices are developed and deployed in an attempt to redistribute, replicate, and control service work in a new region.

However, the offshoring industry confronts a number of social and technical challenges in a new geographical region. Differences in work force skills, training, language, culture, institutional contexts, and industrial practices provide numerous challenges to the redistribution and recovery of industrial practices elsewhere (Krishna et al. 2004). In response, numerous people become involved in the construction of IT and industrial systems in order to recover and recreate industrial work practices that emulate the desires of foreign customers within a new region. We refer to these managerial and employee activities as boundary work, and the various logics that tentatively link the exchange of time, money, attention and work across social and technical participants, as boundary objects.

In this paper, we explore the boundary work and objects involved in the call center offshoring industry in India. We examine the challenges of constructing boundary objects that link the heterogeneous interests of diverse groups in this industry - employees, managers, customers, and offshoring clients - with each other. We draw upon the definition of boundary objects from Star and Griesemer (1989) as the things which are "both plastic enough to adapt to local needs and constraints of the several parties employing them, yet robust enough to maintain a common identify across sites....Like a black board, a boundary object 'sits in the middle' of a group of actors with divergent viewpoints" (p. 46).

Boundary objects have been used in information systems research to understand boundary spanning across communities through IT boundary objects (Gasson 2006). Such boundary objects hold important implications for the design and use of IT artefacts (Karsten et al. 2001). The boundary objects we consider in this case move beyond the purely IT to other objects consistent with Star and Griesemer's definition. In our case, these include offshoring logics, process controls, training, and operations management. These techniques and procedures are used to produce boundary objects that are plastic enough to adapt to local needs and constraints, but common enough to produce an exchange that maintains the interests of the supplier and the receiver of the exchange. Without needing to explicitly identify Western customers and clients, we can identify the boundary objects employed across managers and employees in order to translate the heterogeneous group interests in the production of a call center industry in India. In doing so, we address and complicate both utopian and dystopian views of call center work by illustrating the extensive work required by managers and employees to realize the call center service sector in India. However, by considering this as boundary work, we question both utopian and dystopian views of call center work by suggesting that while it may appear to be a one-side relationship, the challenges of employee turnover and the increasing mobility of call center employees is challenging the viability of this industrial system in the long-term. 


\section{CASE BACKGROUND}

A call center is defined "as a dedicated operation in which computer-utilizing employees receive inbound - or make outbound - telephone calls, with those called processed and controlled either by an Automatic Call Distribution (ACD) or predictive dialing system" (Taylor and Bain 1999, p. 102). Call centers use a number of IT tools to manage telephone calls, customer data, workflow processes, and quality control systems.

A vision of a call center is as a flexible, friendly and knowledge-based workplace staffed by cooperative employees, smiling down the phone as they help the customer, who enhance the image of an organization (Bain and Taylor 2000, p. 3). This view of a call center shows employees as empowered in their identification of customer needs, and to provide relevant service through appropriate support from information technology (Frenkel et al. 1998).

The opposite and dystopian view is that call centers are an electronic panopticon, where complete control over the employees is possible through the integration of telephony and computing (Fernie and Metcalf 1997). Call centers are characterized as sweatshops, with rows of agents in cubicles, answering call after call, while under constant surveillance and pressure by management (Belt et al. 2000). The process is labeled as "assembly line in the head" (Taylor and Bain 1999, p. 107) or "Taylorisation of the white-collar work in call centers" (Richardson and Howcroft 2006, p. 60).

Call center costs in India can be one-third the cost in Western countries, largely through cheaper labor costs (Dossani and Kenney 2003). Despite the cost savings attraction, Richardson and Howcroft (2006) suggest that the complete routinization and standardization of the call center is very difficult. For example, attempts to recruit and retain certain employees who can speak a language have been problematic (Callaghan and Thompson, 2002). We believe that these attempts to construct this industry reflect a larger problem of managing the quality and quantity in call center settings (Taylor and Bain, 1999), and reflect the boundary work and construction of objects, such as computer systems and training practices, which can translate and enrol the diverse participant interests involved in the outsourced call center.

In summary, call centers are, to a large extent, both a dream and an ever-shifting reality for those involved in building the complex socio-technical logics that will enroll not only outsourcers, but the managers and workers in the call center. The work involved in making this happen is nuanced and complex, and therefore far from the simplicity of automation. We explore this boundary work next.

\section{METHODOLOGY}

A qualitative case study (Yin 2003) of three call centers in India was conducted between 2003 and 2007. Data was primarily collected through 23 semi-structured interviews with various managers and call center agents. The companies examined were all located in Bangalore, a hotbed of IT off-shoring in India. The interviews were focused on understanding the nature of managerial work, and their struggles to manage the heterogeneous groups and interests involved in the call center industry. In addition, industry consultants and advisors were also interviewed in order to gain general insights 
into the development of the industry in India. The data was interpreted and organized according to theoretical ideas in boundary work and objects, and are discussed in the findings section (Walsham 2006). In order to understand the nature of the industry, and the role of information technology in relation to call center work, we have chosen to analyze the data at an industrial level, rather than the organizational level (Chiasson and Davidson, 2005).

\title{
4 FINDINGS: BOUNDARY OBJECTS
}

\subsection{The Offshoring Logics}

Since the mid-1990s, many organizations have offshored various services to developing economies such as India. Consequently, business process outsourcing (BPO) has been one of the fastest growing sectors in India since the mid-1990s. The success of early adopters, such as American Express and General Electric, has convinced others to consider the same.

Despite a common perception that call centers are modern day sweatshops, the managers we interviewed believe that a call center agents' salaries are still relatively good for fresh graduates in a job market with limited opportunities. As one industry human resources manager comments,

\begin{abstract}
All call centers are like that-if you look at the population, the profiles of people working in call centers - most of them will be fresh college grads, people with 2 to 3 years of experience, whom the rest of the industry or the rest of the world wouldn't touch 4 to 5 years ago. Today these guys are going in there and making as much money as anybody else did sometime back.
\end{abstract}

Combined with this relative salary potential, a rapid growth of the industry in India has lead to new call centers opening every other day. Trained call center staff are now being poached with small salary increments, which has rapidly escalated salaries and recruitment costs. Despite employment opportunities, call center staff also feel their work is a temporary career option, especially since few move from answering calls into managerial roles. As a result, fresh graduates enter the industry in order to earn money before moving on to other educational or career options.

Beyond these economic and workforce issues, managers also suggest that despite a perception of offshoring driven by only cost-efficiencies, they claim that the specificity of making call centers work in India involves numerous business and cultural logics in order to satisfy the diverse interests of the various groups involved in this industry. Given this, we turn toward the nature of the boundary work and objects used to support exchange across these diverse participants.

\subsection{Process Controls}

Within the call center, organizational processes are facilitated by numerous IT systems, such as shared databases of customer information, call routing, load balancing, 
monitoring etc. The systems mediate the exchange of information, advice, outsourcer scripts, and call center work across the heterogeneous interests involved in the call center industry.

Standardized scripts prompted by information systems are meant to preserve and manage key managerial objectives in call center conversations, including the necessity to deal with calls both quickly and effectively. In organizations where such scripts are not provided, other "quality" practices are used, such as the checking of 30 or 40 conversational elements in recorded calls. The parameters include greeting, proper addressing of customer, identifying customer queries, providing relevant advice, identifying sales opportunities, etc. The analysis is then fed back to the agent, through their coach or team leader. As the head of quality at a call center commented,

\section{It allows teams of people who listen to calls to identify systems aspect problems} and various processes and then give feedback back to management. So the focus here is on very specific processes.

The work involved in designing the systems to measure every second of an agent's time are extensive and almost panopticon. However, even the most stringent boundary object requires adjustment. Although the management is generally interested in the quantity of calls, they have also increased their focus on quality because too much quantity can be detrimental to quality. In order to counteract the growing quantity but decreased quality of calls, small teams have organized weekly competitions in order to encourage both higher quality and quantity targets, recognizing those who manage to produce minimal quality triggers. The result is a revised system of boundary objects in order to manage the complexity of quality that involves considerable effort from all groups.

\subsection{Agent Training}

Quality considerations also moves us into the numerous and complex practices and logics required to achieve it. Outsourcers typically relocate call centers based on the simple premise that achieving a certain quality of interaction among Western native English speakers and English speaking Indians is possible with a huge cost savings to the organization. However, the call is affected by numerous cultural, language, and accent differences with the customers. With only process knowledge, agent conversations with Western customers involve two complex and competing objectives. They have to work at keeping the conversation natural, with a neutral accent, while also exchanging relevant knowledge within a certain time period.

To do so, significant work is required in call center training. Agent training generally lasts six weeks, and spans general as well as call and conversational skills. Organizations began by training agents with American accents, but many now use a neutral accent as a result of difficulties in realizing a pure regional accent. Instead, combined with a neutral accent, they train agents to choose and use common phrases familiar to target customers, rather than mimicking a specific customer accent.

Through emphasizing these softer skills, the training involves difficult and complex boundary work to capture and represent a culture. One head of quality suggests that as the industry matures, the responses of Indian call center agents will begin to match Western expectations: 
[Quality] doesn't have to do with the [call] process. But it has to do with the confidence level, it has to do with a lot of software issues, confidence with which the majority of the people in the U.S. will approach the call or take the callers is much higher than a consultant [agent] over here.

Despite the apparent dominating and controlling logic of call center training, the agents believe the training prepares them to talk to people from diverse cultures, and provides an opportunity for better work and career prospects. They are trained to speak in certain ways, look for cues in the customers' conversation, and familiarize themselves, where possible, with customer's local information such as sports, weather, etc. As a result, both the managers and the employees, through boundary work and objects involved in cultural and linguistic training, achieve their separate interests: standardized quality of service, the management of call quantities, and career mobility.

\subsection{Operations Management}

Despite the extensive training and boundary work in the organization, the industry has created new demands for societal and governmental work. For example, the new call centers were affected by poor public transport in large cities, which created difficulties in achieving operational stability during agent shift changes. As one industry analyst noted,

We had to arrange transport, and even organize lunch to ensure employees were available when their shifts began.

A general manager at a call center commented,

People are picked up and dropped from their residence-door-to-door pickup. No other industry is doing that today. They get a free duty meal. This duty meal is checked on a regular basis; the dieticians control the amount of calories, the food committee which comprises of people in this organization who lay down what they like. So we kind of align ourselves, that we are here for you, right? And comfort is certainly very high.

With rapid expansion in the industry, experienced employees are often poached, fueling competitive attrition and instability in workforce expertise. Management has found it difficult to comprehend the attrition despite the "comfortable" work environment in call centers. A coach in a call center commented that he does not understand why agents leave, since they are earning more than most fresh graduates in other jobs, and are employed by Fortune 500 companies. An agent, however, saw attrition as a result of the stress of routine work:

Basically call centers have thousand employees; you can make people take calls for a year, two years, [then] there should be a lateral shift...that is why you have this attrition rate....The stress level is also very high. 
In response, significant managerial work is now focused on addressing the high attrition rates through increased incentives and modifications to organizational practices and labeling. For example, new job titles were added to create the illusion of career progression, along with small but regular increments to pay. Perhaps not surprising, neither has generally solved the attrition problem.

Recently, emphasis has been placed on doing what call centers have rarely done in the past: creating small teams with team leads, in order to mentor and foster agents' needs. One coach commented about his relationship with his team:

The coach plays a very important role in keeping the team intact. Half of them who stay in the company, they love their coaches' work....My team ... they just look forward to the week offs...we hire a transport or a cab and go to Kaveri fishing camps, overnight stay in forests, and things like that.

Despite management perceptions of call center work as comfortable, with good salaries and a good position for surplus graduates, the attraction and retention of agents remains the biggest source of boundary work in the call center industry's ability to continue and expand. With increasing salaries as one of the few remaining options, the industry may eventually undermine the original reasons for the industry's creation - low cost - and either disappear or mutate into another industrial form (Caldwell 2002).

\section{CONTRIBUTIONS AND CONCLUSION}

This discussion raises a number of contributions. The call center industry in India is a contested space where the various and diverse interests among the groups are negotiated and temporarily connected through boundary work and boundary objects. These boundary objects often include embedded IT artefacts in an attempt to replicate and stabilize work practices and their effects. The result is more of a negotiated truce than a stable order, rendered possible through the temporary use of boundary objects and work.

Our work illustrates that the easy replication of call center work to other low-cost regions hides the extensive boundary work and boundary objects required to navigate across intergroup ties within the industry. The case illustrates a shifting set of boundary "fronts," where managers, outsourcers, outsourcees, and employees are involved in the shifting features of this service industry.

Boundary work and object perspectives on call center work also provide a new perspective on a purely dystopian and utopian view of call center work. In the dystopian case, workers are restricted and imprisoned individuals with few options, while in the utopian case, workers have pure and unrestricted agency to pursue a knowledge-based career. Our case shows that mechanistic attempts to render the dystopian sweatshop by management have produced high employee turnover and the poaching of employees to other firms. This suggests that the employee is not a complete prisoner of circumstances. At the same time, the utopian views, which suggest that call centers are an important part of the new Indian economy and a stepping-stone for development, need to experience the hard and monotonous conditions of call center work, driven by a need to satisfy quantity (i.e., standardization) and cost-related interests. The boundary work and object view of 
call centers illustrates many emergent and competing outcomes for the heterogeneous interests of numerous groups, and the attempts to reconcile these diverse interests through boundary work and boundary objects. In this case, information technology has increased the reach of remote practices and logics from Western companies, which both affect and are affected and transformed by the social and technical settings in which they are recovered.

Here, the IT artefact plays a political role in a complex game of attraction and separation, in the post-structural possibilities of various "productive" engagements, made possible by the engagement of various groups. The work here is immense and complex, and the cost-centered hopes of Western companies and the career aspirations of Indian call center workers confront a complex reconciliation of their diverse interests. The boundary work depends and affects the emergent and somewhat unpredictable mixing and translation of diverse group interests, both disciplined and undisciplined, by the exchange across boundary object systems, so that their interests are perceived to be furthered by their continued relationships. This provides a revised direction and focus for call center, service sector, and information systems research and practice.

\section{References}

Belt, V., Richardson, R., and Webster, J. 2000. "Women's Work in the Information Economy: The Case of Telephone Call Centres," Information, Communication and Society (3:3), pp. 366-385.

Caldwell, B. 2002. "Outsourcing Cost Reduction Creates Paradox: How to Still Make a Profit," Gartner Dataquest, Stamford, CT.

Callaghan, G., and Thompson, P. 2002. "We Recruit Attitude: The Selection and Shaping of Routine Call Centre Labour," Journal of Management Studies (39:2), pp. 233-254.

Chiasson, M. W., and Davidson, E. 2005. "Taking Industry Seriously in Information Systems Research," MIS Quarterly. 29 (4), pp. 591-605

Dossani, R., and Kenney, M. 2003. "Went for Cost, Stayed for Quality? Moving the Back Office to India," Berkeley Roundtable on the International Economy, Paper BRIEWP156, August 7 (http://repositories.cdlib.org/brie/BRIEWP156).

Fernie, S., and Metcalf, D. 1997. "(Not) Hanging on the Telephone: Payments Systems in the New Sweatshops," Working Paper 891, Centre for Economic Performance, London School of Economics (http://cep.lse.ac.uk/pubs/download/dp0390.pdf).

Frenkel, S. J., Tam, M., Korczynski, M., and Shire, K. 1998. "Beyond Bureaucracy? Work Organization in Call Centers," International Journal of Human Resource Management (9:6), pp. 957-979.

Gasson, S. 2006. “A Genealogical Study of Boundary-Spanning IS Design,” European Journal of Information Systems (15:1), pp. 26-41.

Karsten, H., Lyytinen, K., Hurskainen, M., and Koskelainen, T. 2001. "Crossing Boundaries and Conscripting Participation: Representing and Integrating Knowledge in a Paper Machinery Project," European Journal of Information Systems (10:2), pp. 89-98.

Krishna, S., Sahay, S., and Walsham, G. 2004. "Managing Cross-Cultural Issues in Global Software Outsourcing," Communications of the ACM (47:4), pp. 62-66.

Richardson, H. J., and Howcroft, D. 2006. "The Contradictions of CRM-A Critical Lens on Call Centres," Information and Organization (16:1), pp. 56-81.

Star, S. L., and Griesemer, J. R. 1989. "Institutional Ecology 'Translations' and Boundary Objects: Amateurs and Professionals in Berkeley's Museum of Vertebrate Zoology, 190739," Social Studies of Science (19), pp. 387-420. 
Taylor, P., and Bain, P. 1999. “"An Assembly Line in the Head': Work and Employee Relations in the Call Cente," Industrial Relations Journal (30:2), pp. 101-117.

Walsham, G. 2006. "Doing Interpretive Research," European Journal of Information Systems (15:3), pp. 320-330.

Yin R K. 2003. Case Study Research: Design and Methods (3 ${ }^{\text {rd }}$ ed.), Beverly Hills, CA: Sage Publications.

\section{About the Authors}

Paul Devadoss is a lecturer at the Department of Management Science, Lancaster University Management School, UK. He completed his Ph.D. in Information Systems at the School of Computing in the National University of Singapore. His research interests include enterprise systems and e-governments. In particular, he is interested in the social impacts of IT use in organizational settings and the managerial implications of technology use. He has previously published in journals such as Decision Support Systems, MIS Quarterly Executive, Communications of the AIS, Information and Management, and IEEE Transactions on IT in Biomedicine. Paul can be reached by e-mail at paul@davadoss.org.

Mike Chiasson is currently an AIM (Advanced Institute of Management) Innovation Fellow and a Senior Lecturer at Lancaster University's Management School, in the Department of Management Science. Before joining Lancaster University, he was an associate professor in the Haskayne School of Business, University of Calgary, and a postdoctoral fellow at the Institute for Health Promotion Research at the University of British Columbia. His research examines how social context affects IS development and implementation, using a range of social theories (actor network theory, structuration theory, critical social theory, ethnomethodology, communicative action, power knowledge, deconstruction, and institutional theory). In studying these questions, he has examined various development and implementation issues (privacy, user involvement, diffusion, outsourcing, cyber-crime, and system development conflict) within medical, legal, engineering, entrepreneurial, and governmental settings. Most of his work has been qualitative in nature, with a strong emphasis on participant observation. Mike can be reached at m.chiasson@lancaster.ac.uk. 